Article

\title{
Electrical Conductivity and Compressive Strength of Cement Paste with Multiwalled Carbon Nanotubes and Graphene Nanoplatelets
}

\author{
Kwang Mo Lim ${ }^{1}$ (D) and Joo Ha Lee ${ }^{2, *(\mathbb{D})}$ \\ 1 Korean Peninsula Infrastructure Special Committee, Korea Institute of Civil Engineering and Building \\ Technology, Goyang-si 10223, Korea; limkm@kict.re.kr \\ 2 Department of Civil and Environmental Engineering, The University of Suwon, Hwaseong-si 18323, Korea \\ * Correspondence: leejooha@suwon.ac.kr; Tel.: +82-31-220-2159
}

Citation: Lim, K.M.; Lee, J.H Electrical Conductivity and Compressive Strength of Cement Paste with Multiwalled Carbon Nanotubes and Graphene Nanoplatelets. Appl. Sci. 2022, 12 , 1160. https://doi.org/10.3390/ app12031160

Academic Editor: Chao-Wei Tang

Received: 19 December 2021

Accepted: 21 January 2022

Published: 23 January 2022

Publisher's Note: MDPI stays neutral with regard to jurisdictional claims in published maps and institutional affiliations.

Copyright: (C) 2022 by the authors. Licensee MDPI, Basel, Switzerland. This article is an open access article distributed under the terms and conditions of the Creative Commons Attribution (CC BY) license (https:// creativecommons.org/licenses/by/ $4.0 /)$.

\begin{abstract}
Many studies have been conducted using carbon-based nanomaterials (CBNs) for improving the electrical conductivity and mechanical properties of cementitious composites, but their practical use is yet to be achieved. Several methods have been attempted to secure the dispersibility in the cementitious composite matrix of CBNs, such as multiwalled carbon nanotubes (MWCNTs) and graphene nanoplatelets (GNPs). In this study, MWCNTs and GNPs were noncovalently functionalized using melamine, a low-cost chemical, and ball milling, a simple process commonly used in industrial fields. Additionally, MWCNTs and GNPs having one- and two-dimensional shapes were mixed with the cement paste to examine their effect on electrical conductivity and compressive strength. Following the experiment, it was shown that the electrical conductivity was improved via the noncovalent functionalization of MWCNT and GNP. The compressive strength increased up to approximately $0.30-0.60 \%$ of the CBNs content; however, for CBN content higher than $0.60 \%$, the compressive strength decreased. The hybrid MWCNT and GNP mixture had a negligible effect on the electrical conductivity and compressive strength.
\end{abstract}

Keywords: MWCNTs; GNPs; functionalization; conductivity; compressive strength; cement paste

\section{Introduction}

General concrete is limited in its use as a load-bearing construction material. However, in recent years, as the demand for smart construction technology continues to grow, there have been continuous attempts to give concrete various functions in addition to basic structural performance [1]. One such attempt involves using various carbon-based nanomaterials (CBNs) to improve the strength, thermal properties, and electrical conductivity of cementitious composites [2]. Carbon nanotubes (CNTs) are among the most interesting of these materials. After the first multiwalled carbon nanotube (MWCNT) was discovered by Iijima [3] during the observation of a carbon byproduct that was generated using an arc between two carbon electrodes, CNTs have been objects of interest for many researchers. CNTs can be classified into single-walled CNTs or MWCNTs depending on the number of graphene layers. MWCNTs are most commonly used in cementitious composites owing to their high elasticity modulus, tensile strength, and excellent thermal and electrical conductivities [4]. There have been many studies on the effect of MWCNTs on the properties of concrete, mortar, paste, polymers, and other composites [5,6]. On the other hand, for graphene nanoplatelets (GNPs) comprising several layers of graphene sheets, owing to its two-dimensional (2D) structure having a relatively large specific surface area and a large surface-volume ratio compared with other CBNs, researchers have great interest in its use as a nano-reinforcing material for cementitious composites [7].

Several studies showed that the incorporation of MWCNTs improves mechanical properties, such as the compressive, tensile, and flexural strengths of cement, mortar, or 
paste [8-15]. In most cases, the strength increases as the content of MWCNT increases but decreases above a certain content ratio. However, the optimal incorporation and strength-increasing rates were reported with different results by various researchers [8-15]. Conversely, several studies indicated its negative effects on mechanical performance [16-20]. However, finding a clear correlation between the incorporation rate of MWCNTs and decreasing strength was difficult. Many studies used GNPs to improve the mechanical properties of cementitious composites [21-26], whereas other studies found that the use of GNPs had little to no effect on strength [27-29].

It is a well-known fact that through the incorporation of CBNs, e.g., MWCNTs and GNPs, electrical conductivity can be imparted to cementitious composites. However, while the optimal mixture ratio and electrical conductivity were reported differently, there is uniform agreement that dispersing mixed CBNs evenly in the cement matrix is an important factor for improving electrical conductivity. CBNs tend to agglomerate owing to van der Waals forces; therefore, researchers have experienced difficulty dispersing them uniformly in a cement matrix. To date, no established standard exists for the dispersing method of CBNs; these include noncovalent approaches, such as surfactant and ultrasonication, and covalent approaches, such as acid etching. Many researchers concluded that CBNs, such as MWCNTs or GNPs, should be functionalized for the best performance when mixed into cementitious composites [5].

Kim et al. [30] proposed a method for the noncovalent functionalization of GNPs using a ball-milling process with melamine to improve their interfacial adhesion and dispersion in an epoxy matrix. In this study, the method suggested by Kim et al. was used to homogeneously disperse the MWCNT or GNP in a cement paste matrix and compared this approach with ultrasonication, which is the most common dispersing method [30]. Most of the existing studies investigated the properties of cementitious composites by individually incorporating MWCNTs or GNPs. As only a few studies exist on hybrid cementitious composites in which two CBNs are simultaneously mixed, the compressive strength and the electrical conductivity of the hybrid cement pastes mixed with MWCNTs and GNPs were investigated in this study [31,32].

\section{Experimental Design}

\subsection{Mix Proportions}

In this study, a cement paste was mixed without fine and coarse aggregates. Type I ordinary Portland cement was used, and the water-cement ratio was fixed at $42 \%$. The CBNs used in the mixture were MWCNTs and GNPs, the properties of which are shown in Tables 1 and 2. One of the main experimental variables was the content of CBNs, which was determined based on previous studies $[5,8-15,21-26]$ so that the percolation zone for mechanical properties and electrical conductivity could be observed; the MWCNTs and GNPs were incorporated at $0.06 \%, 0.12 \%, 0.30 \%, 0.60 \%$, and $1.20 \%$ of the cement weight, respectively. Additionally, the hybrid mixture of MWCNTs and GNPs was also set as an experimental variable. GNPs have a plane-shaped molecular structure, whereas MWCNTs have a cylindrical molecular shape resembling rolled-up graphene. The simultaneous mixture of two differently shaped CBNs is expected to be effective at forming a conductive network owing to the mutually complementary interaction. To confirm this synergistic effect, MWCNTs and GNPs were hybrid mixed in a 1:1 ratio to reach a combined weight of $0.12 \%, 0.60 \%$, and $1.20 \%$ of the cement weight. The experimental variables are shown in Table 3.

Table 1. Properties of multiwalled carbon nanotubes (MWCNTs).

\begin{tabular}{ccccc}
\hline $\begin{array}{c}\text { Specific Surface Area } \\
\left(\mathbf{m}^{2} / \mathbf{g}\right)\end{array}$ & $\begin{array}{c}\text { Bulk Density } \\
\left(\mathrm{g} / \mathrm{cm}^{3}\right)\end{array}$ & $\begin{array}{c}\text { Purity } \\
(\%)\end{array}$ & $\begin{array}{c}\text { Outer Diameter } \\
(\mathbf{n m})\end{array}$ & $\begin{array}{c}\text { Length } \\
(\boldsymbol{\mu m})\end{array}$ \\
\hline $150-250$ & $0.04-0.08$ & $>90$ & $5-20$ & $10-30$ \\
\hline
\end{tabular}


Table 2. Properties of graphene nanoplatelets (GNPs).

\begin{tabular}{cccc}
\hline $\begin{array}{c}\text { Specific Surface Area } \\
\left(\mathbf{m}^{2} / \mathbf{g}\right)\end{array}$ & $\begin{array}{c}\text { Bulk Density } \\
\left(\mathbf{g} / \mathbf{c m}^{\mathbf{3}}\right)\end{array}$ & $\begin{array}{c}\text { Purity } \\
\mathbf{( \% )}\end{array}$ & $\begin{array}{c}\text { Diameter } \\
(\mu \mathbf{m})\end{array}$ \\
\hline $30-60$ & $0.03-0.1$ & $>95$ & $7-25$ \\
\hline
\end{tabular}

Table 3. Experimental variables.

\begin{tabular}{|c|c|c|c|}
\hline Mix ID. & Dispersion & $\begin{array}{c}\text { MWCNTs } \\
(\mathbf{w t} \%)\end{array}$ & $\begin{array}{l}\text { GNPs } \\
(w t \%)\end{array}$ \\
\hline \multirow{5}{*}{ MWCNT } & \multirow{13}{*}{ Ultrasonication } & 0.06 & - \\
\hline & & 0.12 & - \\
\hline & & 0.30 & - \\
\hline & & 0.60 & - \\
\hline & & 1.20 & - \\
\hline \multirow{5}{*}{ GNP } & & - & 0.06 \\
\hline & & - & 0.12 \\
\hline & & - & 0.30 \\
\hline & & - & 0.60 \\
\hline & & - & 1.20 \\
\hline \multirow{3}{*}{ Hybrid } & & 0.06 & 0.06 \\
\hline & & 0.30 & 0.30 \\
\hline & & 0.60 & 0.60 \\
\hline \multirow{5}{*}{ f-MWCNT } & \multirow{13}{*}{$\begin{array}{c}\text { Noncovalent } \\
\text { functionalization } \\
+ \\
\text { ultrasonication }\end{array}$} & 0.06 & - \\
\hline & & 0.12 & - \\
\hline & & 0.30 & - \\
\hline & & 0.60 & - \\
\hline & & 1.20 & - \\
\hline & & - & 0.06 \\
\hline & & - & 0.12 \\
\hline f-GNP & & - & 0.30 \\
\hline & & - & 0.60 \\
\hline & & - & 1.20 \\
\hline \multirow{3}{*}{ f-Hybrid } & & 0.06 & 0.06 \\
\hline & & 0.30 & 0.30 \\
\hline & & 0.60 & 0.60 \\
\hline
\end{tabular}

\subsection{Dispersion of MWCNTs and GNPS}

An additional experimental variable is whether MWCNTs and GNPs were functionalized. Owing to their hydrophobic properties, CBNs have difficulty securing dispersibility, even when mixed in water. The cohesion between the carbon particles of MWCNTs and GNPs by the strong van der Waals force results in the agglomeration of CBNs, leading to the formation of clusters and bundles when dispersed in a solution. To avoid such aggregation and uniformly disperse CBNs without breakage, a combination of chemical and physical methods must be implemented [33]. That is, a physical method of separating CBNs individually by applying ultrasonic energy and a chemical treatment method that involves modifying and functionalizing the surface of $\mathrm{CBNs}$ to prevent re-agglomeration following ultrasonication should be performed simultaneously. This study investigated the effect of securing dispersibility through functionalization on conductivity. The MWCNTs and GNPs were noncovalent functionalized using the process proposed by Kim et al. [30]. The functionalization process performed in this study is shown in Figure 1. First, CBNs were mixed with melamine in a 1:1 ratio and ultrasonicated in dimethylformamide (DMF, a polar solvent) for $1 \mathrm{~h}$ to produce the mixture (Figure 1a). The ultrasonication-treated mixed solution was poured into a polypropylene bottle containing stainless steel balls, and ball milling was performed for $24 \mathrm{~h}$ (Figure $1 \mathrm{~b}$ ). After the synthesis of CBNs and melamine 
via ball milling, the DMF was washed through filtration using ethanol and distilled water (Figure 1c). It was then dried in a vacuum oven for $24 \mathrm{~h}$ to produce functionalized MWCNTs and GNPs. To produce the specimens, functionalized MWCNTs or GNPs were added to the mixed water, underwent ultrasonication for $30 \mathrm{~min}$, and was then mixed with the cement for $10 \mathrm{~min}$ at $300 \mathrm{rpm}$ using a mortar mixer. The control group did not go through the functionalization and underwent ultrasonication for $30 \mathrm{~min}$ and mortar mixing for only $10 \mathrm{~min}$.

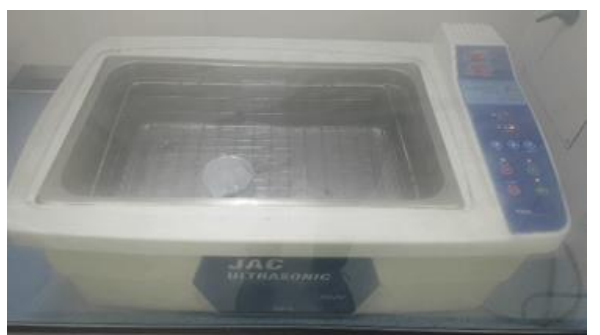

(a)

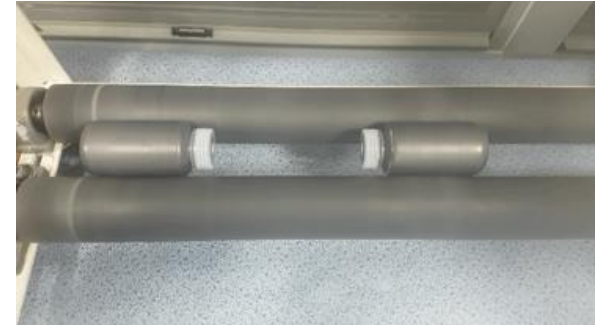

(b)

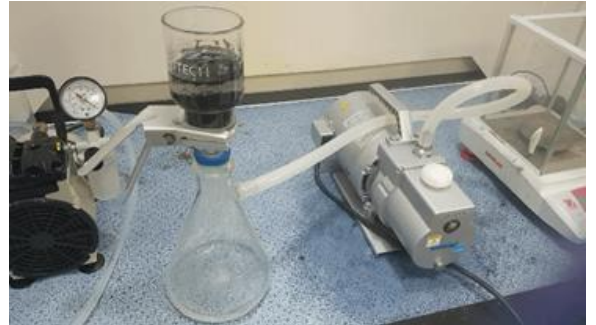

(c)

Figure 1. Noncovalent functionalization of MWCNTs and GNPs: (a) ultrasonication of MWCNTs or GNPs with melamine in DMF, (b) ball milling, and (c) washing.

\subsection{Electrical Resistivity and Compressive Strength Test}

Electrical conductivity and compressive strength were measured for various mixes, as shown in Table 2. Three $50 \mathrm{~mm}$ cubic specimens were used for each test. All specimens were cured under a constant temperature $\left(20 \pm 2{ }^{\circ} \mathrm{C}\right)$ and relative humidity $(50 \pm 4 \%)$ for 28 days. The compressive strength was measured according to the Korean Industrial Standards L 5105 [34]. Electrical resistance was measured using the commonly used 2-point uniaxial method. The voltage difference was applied to both sides of the specimen, to which the copper plate was attached using conductive epoxy. Electrical resistivity was obtained by substituting the amount of current into Equation (1) according to Ohm's law. When the electrical conduction path of the specimen is not uniform, a polarization effect can occur, i.e., the electrical resistance of the specimen may increase during the measurement [35]. Therefore, an electrical resistance measurement was performed within $1 \mathrm{~s}$ to minimize this effect.

$$
\rho=R \frac{A}{L}
$$

where $\rho, R, A$, and $L$ are the electrical resistivity $(\Omega \mathrm{m})$, measured resistance $(\Omega)$, electrode area $\left(\mathrm{m}^{2}\right)$, and electrode interval $(\mathrm{m})$, respectively.

\section{Test Results and Discussion}

\subsection{Electrical Resistivity}

The electrical conductivity test results are shown in Figures 2-4. The experimental results were expressed as the average value measured from three specimens, and the standard deviation is indicated on the bar graph.

The effect of the functionalized MWCNTs and GNPs on the electrical resistance is shown in Figure 2. Except for the specimens with the MWCNT mixture ratio of $0.06 \%$ and the hybrid mixture ratio of $0.12 \%$, the functionalized specimens showed lower electrical resistance in all cases. The difference in electrical resistance between the functionalized and nonfunctionalized specimens became larger as the mixture rate was increased to $\geq 0.30 \%$. Improved electrical conductivity, along with the functionalization of MWCNTs, was observed more frequently compared with the GNPs. The electrical resistance of MWCNTs was reduced by an average of 36\% in functionalized specimens with a mixture ratio of $\geq 0.30 \%$ and by an average of $22 \%$ for GNPs. The standard deviation for the electrical resistance of the functionalized specimens was smaller than for the nonfunctionalized 
specimens in all cases. These experimental results showed that the functionalization of MWCNTs and GNPs improved their dispersion in the cement matrix.

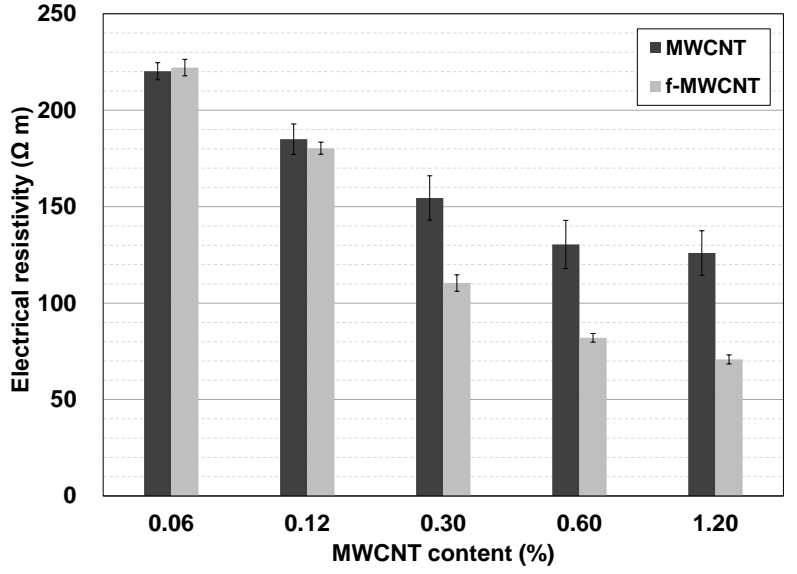

(a)

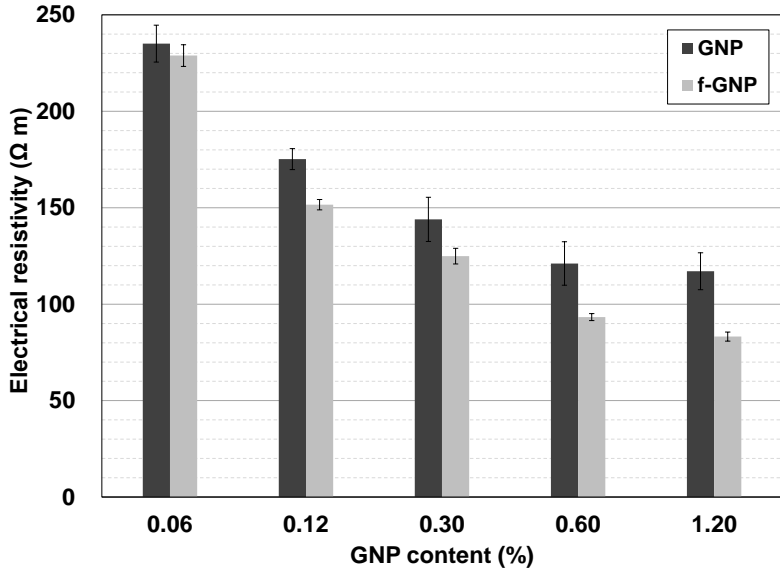

(b)

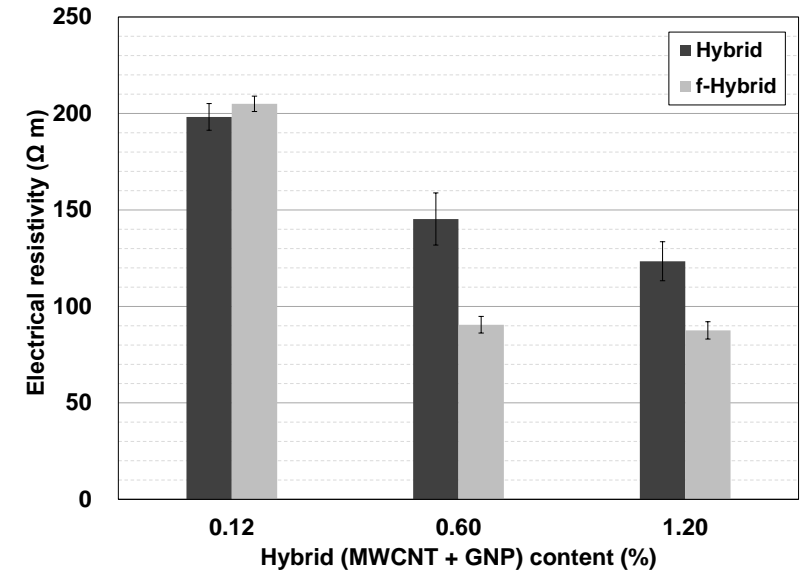

(c)

Figure 2. Effect of functionalization on electrical resistivity: (a) MWCNTs, (b) GNPs, (c) hybrid of MWCNTs and GNPs.

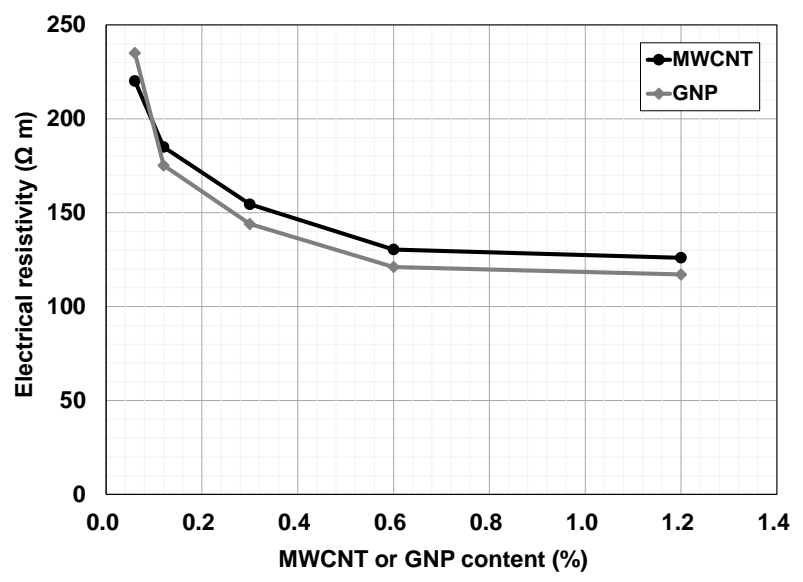

(a)

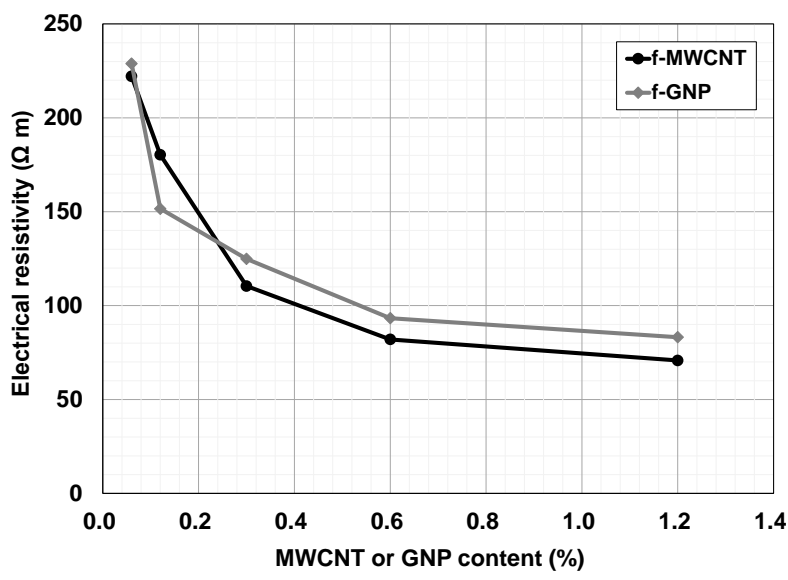

(b)

Figure 3. Effect of the MWCNT or GNP content on electrical resistivity: (a) non-functionalization and (b) functionalization. 


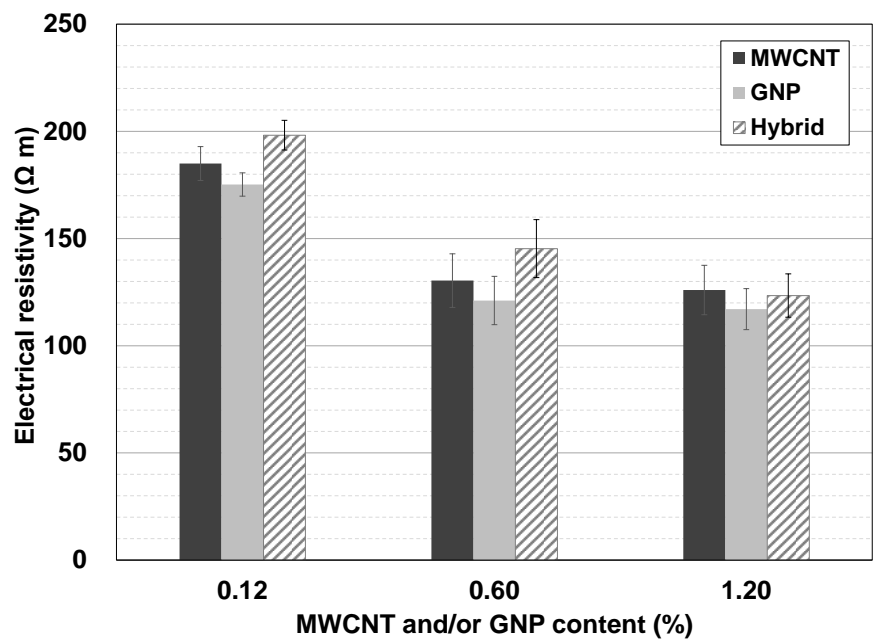

(a)

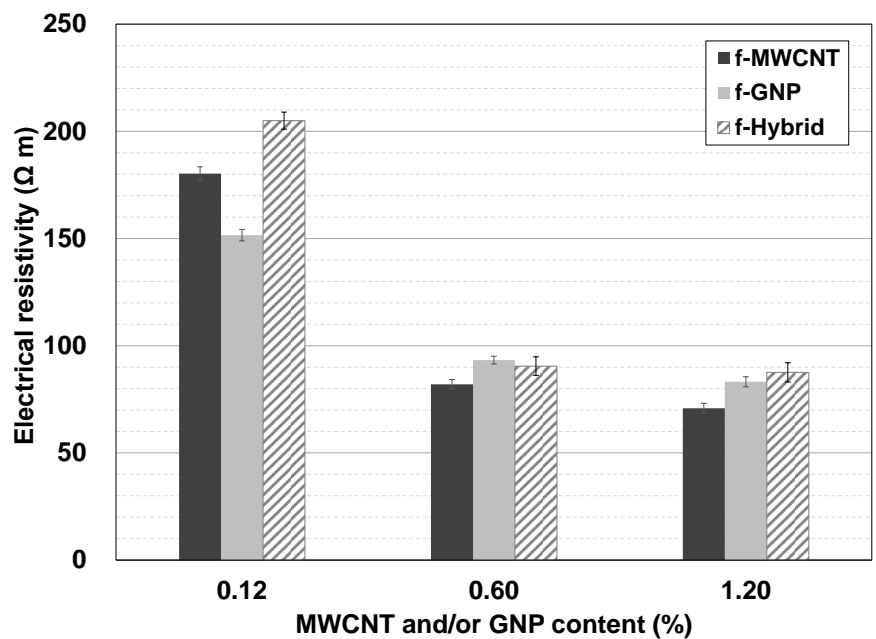

(b)

Figure 4. Effect of hybridization of MWCNTs and GNPs on electrical resistivity: (a) nonfunctionalization and (b) functionalization

Figure 3 shows the electrical resistance changes with respect to the content of MWCNTs and GNPs. The decrease in electrical resistance was generally large up to a content of $0.30 \%$ but slowed thereafter. In nonfunctionalized specimens, the electrical resistance changes were insignificant at $\geq 0.60 \%$. However, although small, the electrical resistance notably continued to decrease in the functionalized specimen. In nonfunctionalized specimens, the GNP was $9.6 \Omega \mathrm{m}$ smaller than MWCNT on average, except for the $0.06 \%$ content. However, in functionalized specimens, the MWCNT was an average of $12.7 \Omega \mathrm{m}$ smaller than the GNP at the content of $\geq 0.30 \%$. At a relatively high content, the dispersion effect of the MWCNT appeared to be larger compared with the GNP as a result of functionalization.

Figure 4 shows the hybrid effect on the electrical resistance of the MWCNTs and GNPs. In the case of hybrid mixing of one-dimensional MWCNTs and 2D GNPs, the electrical resistance was higher than or similar to that of individual mixing, regardless of the functionalization. This result was contrary to the expected effect that hybrid incorporation would provide an advantage in forming conductive networks. Therefore, it was concluded that differently shaped nanomaterials interfered with one another upon dispersion within the cement matrix.

\subsection{Compressive Strength}

Figure 5 shows the effect of the MWCNT and GNP content and functionalization on the compressive strength. Overall, the compressive strength tended to increase as the content of CBNs increased up to the level of $0.30 \%$ to $0.60 \%$, whereas at contents higher than $0.60 \%$, the strength decreased. However, the amount of change in compressive strength in all specimens was within $6 \%$, and its level did not appear to be substantial. When compared with the MWCNT or GNP mixed specimens, the MWCNT showed an overall higher strength than the GNP, regardless of functionalization. Therefore, the shape of the MWCNTs more effectively bridged cracks than the GNPs [31]. The compressive strength of the nonfunctionalized and functionalized specimens was at a similar level, and no apparent tendency was observed for the effect on compressive strength through functionalization. Although some studies showed that excessive functionalization treatment adversely affected the strength of cementitious composites by causing physical damage to the surface of the CBNs, no such defects were found in this study [36]. This may have been because the MWCNTs and GNPs were noncovalently functionalized through the aromatic ring in melamine via $\pi-\pi$ interactions that did not change the surfaces, unlike covalent functionalization [30]. 


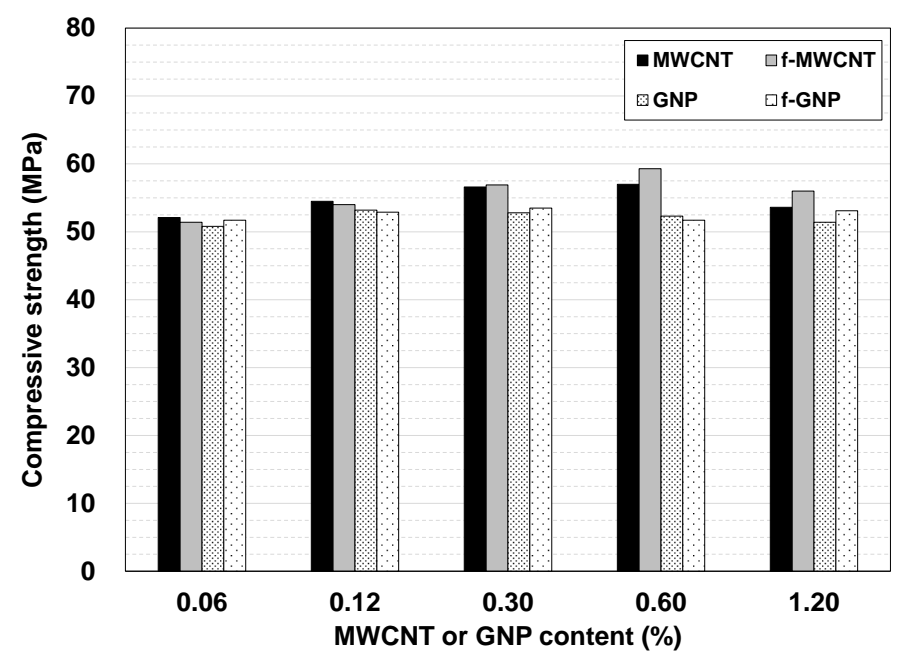

Figure 5. Effect of MWCNT or GNP content on compressive strength.

Figure 6 shows the effect of the hybridizations of MWCNTs and GNPs on the compressive strength. The hybrid did not improve the compressive strength, and no substantial change was observed in the compressive strength with an increase in the hybrid content. However, some studies reported that the hybrid incorporation of CBNs improves mechanical properties, including the compressive strength of cementitious composites [37-40]. Further studies on the effect of hybrid incorporation of CBNs on electrical conductivity and mechanical properties are necessary.

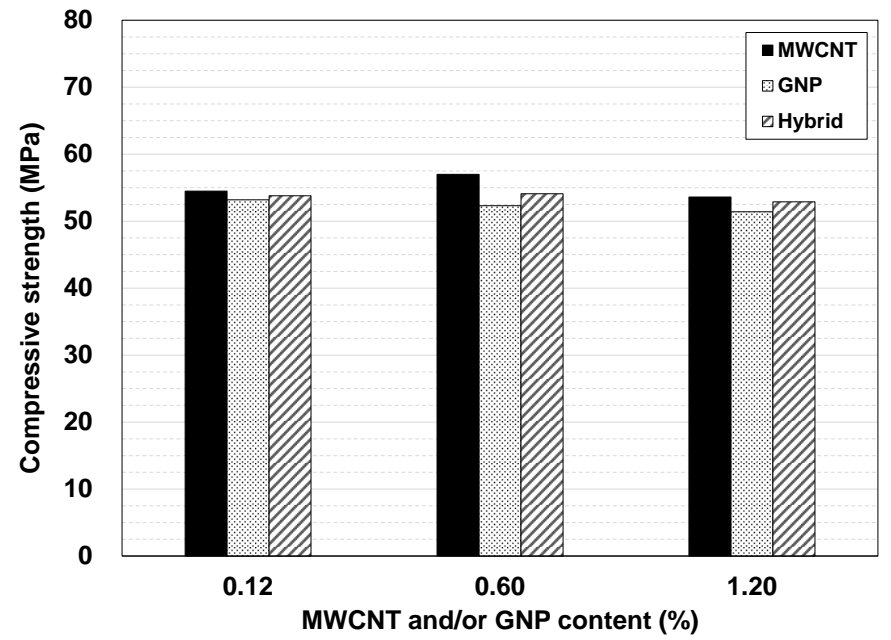

(a)

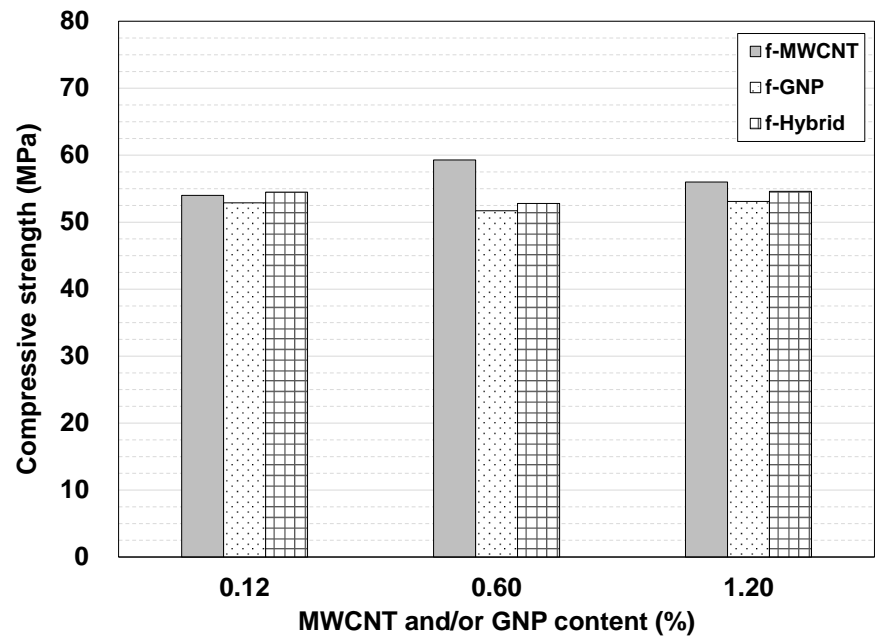

(b)

Figure 6. Effect of the hybridization of MWCNTs and GNPs on the compressive strength: (a) nonfunctionalization and (b) functionalization.

\section{Conclusions}

(1) As a result of comparing the cement paste specimen containing MWCNTs and GNPs that were noncovalently functionalized with melamine using the ball-milling process with the specimen containing MWCNTs and GNPs that were only ultrasonication-treated, the electrical conductivity and dispersibility of the CBNs were improved within the cement matrix using noncovalent functionalization; in particular, the decrease in electrical resistance was larger with a high content of CBNs.

(2) As the MWCNT and GNP content increased, the electrical resistance decreased. However, at an incorporation ratio $\geq 0.3 \%$, the range of decrease in the electrical resistance was small, and there was almost no change at ratios $\geq 0.6 \%$. The compressive strength 
increased up to approximately $0.30-0.60 \%$ of the CBNs content; however, for CBN content higher than $0.60 \%$, the compressive strength decreased. Nonetheless, the variation in compressive strength was not large.

(3) The electrical resistance of the hybrid mixture involving the differently shaped MWCNTs and GNPs was actually larger or similar to that of independently mixed specimens. The effect on the compressive strength of the MWCNT and GNP hybrid was also difficult to determine. The results of the hybrid CBNs on the electrical and mechanical properties of cementitious composites are considered to be different according to the type and content of CBNs; therefore, further research is necessary.

Author Contributions: Conceptualization, J.H.L.; data curation, K.M.L.; writing-original draft preparation, J.H.L.; writing-review and editing, K.M.L. and J.H.L.; supervision, J.H.L.; project administration, J.H.L.; funding acquisition, J.H.L. All authors have read and agreed to the published version of the manuscript.

Funding: This work was supported by a grant (21CTAP-C157478-02) from the Technology Advancement Research Program funded by the Ministry of Land, Infrastructure and Transport of the Korean Government and by a National Research Foundation of Korea (NRF) grant funded by the Korean Government (MSIT) (no. NRF-2021R1F1A1063528).

Conflicts of Interest: The authors declare no conflict of interest.

\section{References}

1. Lin, Y.; Du, H. Graphene reinforced cement composites: A review. Constr. Build. Mater. 2020, 265, 120312. [CrossRef]

2. Raki, L.; Beaudoin, J.; Alizadeh, R.; Makar, J.; Sato, T. Cement and concrete nanoscience and nanotechnology. Materials 2010, 3 , 918. [CrossRef]

3. Iijima, S. Helical microtubules of graphitic carbon. Nature 1991, 354, 56-58. [CrossRef]

4. Makar, J.M.; Beaudoin, J.J. Carbon nanotubes and their application in the construction industry. In Proceedings of the 1st International Symposium on Nanotechnology in Construction, Paisley, Scotland, 23-25 June 2003; pp. 331-341.

5. Assi, L.; Alsalman, A.; Bianco, D.; Ziehl, P.; El-Khatib, J.; Bayat, M.; Hussein, F.H. Multiwall carbon nanotubes (MWCNTs) dispersion \& mechanical effects in OPC mortar \& paste: A review. J. Build. Eng. 2021, 43, 102512. [CrossRef]

6. Kaspar, P.; Sobola, D.; Částková, K.; Dallaev, R.; Št’astná, E.; Sedlák, P.; Knápek, A.; Trčka, T.; Holcman, V. Case Study of Polyvinylidene Fluoride Doping by Carbon Nanotubes. Materials 2021, 14, 1428. [CrossRef]

7. Jiang, Z.; Sevim, O.; Ozbulut, O.E. Mechanical properties of graphene nanoplatelets-reinforced concrete prepared with different dispersion techniques. Constr. Build. Mater. 2021, 303, 124472. [CrossRef]

8. Mohsen, M.O.; Taha, R.; Abu Taqa, A.; Shaat, A. Optimum carbon nanotubes' content for improving flexural and compressive strength of cement paste. Constr. Build. Mater. 2017, 150, 395-403. [CrossRef]

9. Xu, S.; Liu, J.; Li, Q. Mechanical properties and microstructure of multi-walled carbon nanotube-reinforced cement paste. Constr. Build. Mater. 2015, 76, 16-23. [CrossRef]

10. Naqi, A.; Abbas, N.; Zahra, N.; Hussain, A.; Shabbir, S.Q. Effect of multi-walled carbon nanotubes (MWCNTs) on the strength development of cementitious materials. J. Mater. Res. Technol. 2019, 8, 1203-1211. [CrossRef]

11. Jang, S.-H.; Kawashima, S.; Yin, H. Influence of carbon nanotube clustering on mechanical and electrical properties of cement pastes. Materials 2016, 9, 220. [CrossRef]

12. Du, M.R.; Jing, H.W.; Duan, W.H.; Han, G.S.; Chen, S.J. Methylcellulose stabilized multi-walled carbon nanotubes dispersion for sustainable cement composites. Constr. Build. Mater. 2017, 146, 76-85. [CrossRef]

13. Cui, H.; Yang, S.; Memon, S.A. Development of carbon nanotube modified cement paste with microencapsulated phase-change material for structural-functional integrated application. Int. J. Mol. Sci. 2015, 16, 8027-8039. [CrossRef]

14. Sikora, P.; Abd Elrahman, M.; Chung, S.-Y.; Cendrowski, K.; Mijowska, E.; Stephan, D. Mechanical and microstructural properties of cement pastes containing carbon nanotubes and carbon nanotube-silica core-shell structures, exposed to elevated temperature. Cement Concr. Compos. 2019, 95, 193-204. [CrossRef]

15. Guan, X.; Bai, S.; Li, H.; Ou, J. Mechanical properties and microstructure of multiwalled carbon nanotube-reinforced cementitious composites under the early-age freezing conditions. Constr. Build. Mater. 2020, 233, 117317. [CrossRef]

16. Konsta-Gdoutos, M.S.; Batis, G.; Danoglidis, P.A.; Zacharopoulou, A.K.; Zacharopoulou, E.K.; Falara, M.G.; Shah, S.P. Effect of $\mathrm{CNT}$ and CNF loading and count on the corrosion resistance, conductivity and mechanical properties of nanomodified OPC mortars. Constr. Build. Mater. 2017, 147, 48-57. [CrossRef]

17. Sun, G.; Liang, R.; Lu, Z.; Zhang, J.; Li, Z. Mechanism of cement/carbon nanotube composites with enhanced mechanical properties achieved by interfacial strengthening. Constr. Build. Mater. 2016, 115, 87-92. [CrossRef]

18. Hawreen, A.; Bogas, J.A.; Dias, A.P.S. On the mechanical and shrinkage behavior of cement mortars reinforced with carbon nanotubes. Constr. Build. Mater. 2018, 168, 459-470. [CrossRef] 
19. Falara, M.G.; Aza, C.A.; Danoglidis, P.A.; Konsta-Gdoutos, M.S.; Gdoutos, E.E. Measurement and modeling of the elastic modulus of advanced cement based nanocomposites. In Nanotechnology in Construction; Sobolev, K., Shah, S., Eds.; Springer: Cham, Switzerland, 2015. [CrossRef]

20. Miller, H.D. Surface Treatment of Steel Fibres and Carbon Nanotubes to Develop Chemical Bonds with Concrete. Ph.D. Thesis, University of New South Wales, Sydney, Australia, 2019.

21. Baomin, W.; Shuang, D. Effect and mechanism of graphene nanoplatelets on hydration reaction, mechanical properties and microstructure of cement composites. Constr. Build. Mater. 2019, 228, 116720. [CrossRef]

22. Wang, B.; Shuang, D. Effect of graphene nanoplatelets on the properties, pore structure and microstructure of cement composites. Mater. Express 2018, 8, 407-416. [CrossRef]

23. Wang, B.; Jiang, R.; Wu, Z. Investigation of the mechanical properties and microstructure of graphene nanoplatelet-cement composite. Nanomaterials 2016, 6, 200. [CrossRef]

24. Tao, J.; Wang, X.; Wang, Z.; Zeng, Q. Graphene nanoplatelets as an effective additive to tune the microstructures and piezoresistive properties of cement-based composites. Constr. Build. Mater. 2019, 209, 665-678. [CrossRef]

25. Liu, Q.; Xu, Q.; Yu, Q.; Gao, R.; Tong, T. Experimental investigation on mechanical and piezoresistive properties of cementitious materials containing graphene and graphene oxide nanoplatelets. Constr. Build. Mater. 2016, 127, 565-576. [CrossRef]

26. Jiang, Z.; Sherif, M.M.; Xing, G.; Ozbulut, O.E. Tensile characterization of graphene nanoplatelets (GNP) mortar using acoustic emissions. Mater. Today Commun. 2020, 25, 101433. [CrossRef]

27. Peyvandi, A.; Soroushian, P.; Farhadi, N.; Balachandra, A.M. Evaluation of the reinforcement efficiency of low-cost graphite nanomaterials in high-performance concrete. KSCE J. Civ. Eng. 2018, 22, 3875-3882. [CrossRef]

28. Chen, G.; Yang, M.; Xu, L.; Zhang, Y.; Wang, Y. Graphene nanoplatelets impact on concrete in improving freeze-thaw resistance. Appl. Sci. 2019, 9, 3582. [CrossRef]

29. Du, H.; Gao, H.J.; Pang, S.D. Improvement in concrete resistance against water and chloride ingress by adding graphene nanoplatelet. Cem. Concr. Res. 2016, 83, 114-123. [CrossRef]

30. Kim, J.; Cha, J.; Jun, G.H.; Yoo, S.C.; Ryu, S.; Hong, S.H. Fabrication of graphene nanoplatelet/epoxy nanocomposites for lightweight and high-strength structural applications. Part. Part. Syst. Charact. 2018, 35, 1700412. [CrossRef]

31. Xu, J.; Ashraf, S.; Khan, S.; Chen, X.; Akbar, A.; Farooq, F. Micro-cracking pattern recognition of hybrid CNTs/GNPs cement pastes under three-point bending loading using acoustic emission technique. J. Build. Eng. 2021, 42, 102816. [CrossRef]

32. Farcas, C.; Galao, O.; Navarro, R.; Zornoza, E.; Baeza, F.J.; Del Moral, B.; Pla, R.; Garcés, P. Heating and de-icing function in conductive concrete and cement paste with the hybrid addition of carbon nanotubes and graphite products. Smart Mater. Struct. 2021, 30, 045010. [CrossRef]

33. Rao, R.; Sindu, B.S.; Sasmal, S. Synthesis, design and piezo-resistive characteristics of cementitious smart nanocomposites with different types of functionalized MWCNTs under long cyclic loading. Cement Concr. Compos. 2020, 108, 103517. [CrossRef]

34. Testing Method for Compressive Strength of Hydraulic Cement Mortars; KS L 5105; Korean Standards Association: Seoul, Korea, 2017.

35. Cao, J.; Chung, D.D.L. Electric polarization and depolarization in cement-based materials, studied by apparent electrical resistance measurement. Cem. Concr. Res. 2004, 34, 481-485. [CrossRef]

36. Musso, S.; Tulliani, J.-M.; Ferro, G.; Tagliaferro, A. Influence of carbon nanotubes structure on the mechanical behavior of cement composites. Compos. Sci. Technol. 2009, 69, 1985-1990. [CrossRef]

37. Farooq, F.; Akbar, A.; Khushnood, R.A.; Muhammad, W.L.B.; Rehman, S.K.U.; Javed, M.F. Experimental Investigation of Hybrid Carbon Nanotubes and Graphite Nanoplatelets on Rheology, Shrinkage, Mechanical, and Microstructure of SCCM. Materials 2020, 13, 230. [CrossRef] [PubMed]

38. Abedi, M.; Fangueiro, R.; Camões, A.; Correia, A.G. Evaluation of CNT/GNP's synergic effects on the Mechanical, Microstructural, and durability properties of a cementitious composite by the novel dispersion method. Constr. Build. Mater. 2020, 260, 120486. [CrossRef]

39. Zhou, C.; Li, F.; Hu, J.; Ren, M.; Wei, J.; Yu, Q. Enhanced mechanical properties of cement paste by hybrid graphene oxide/carbon nanotubes. Constr. Build. Mater. 2017, 134, 336-345. [CrossRef]

40. Li, X.; Wei, W.; Qin, H.; Hu, Y.H. Co-effects of graphene oxide sheets and single wall carbon nanotubes on mechanical properties of cement. J. Phys. Chem. Solids. 2015, 85, 39-43. [CrossRef] 